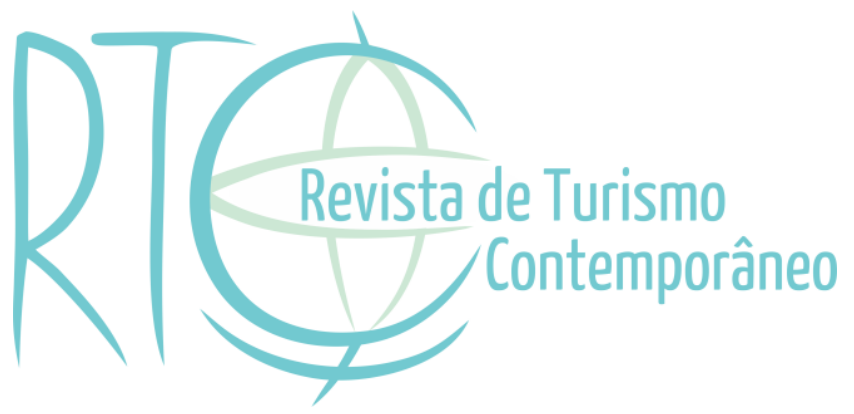

\title{
Fazendas, agricultura familiar e antigos engenhos de açúcar para viabilidade do turismo rural no litoral sul de Sergipe/Brasil
}

\section{Farms, family agriculture and old sugar mills to viability of rural tourism on the coast south of Sergipe/Brazil}

\section{Ivan Rêgo Aragão}

Coordenador do Curso EaD Médio-Tec em Guia de Turismo do Instituto Federal de Sergipe IFS, Aracaju/SE, Brasil

E-mail: ivan_culturaeturismo@hotmail.com

\section{Gabriela Nicolau dos Santos}

Consultora sênior de Turismo da Companhia Brasileira de Projetos e Empreendimentos Cobrape, Aracaju/SE, Brasil

E-mail: gabrielanicolau.80@gmail.com 


\section{RESUMO}

O presente estudo contemplou o processo de viabilidade do turismo rural no litoral sul de Sergipe, abragendo os municípios de Itaporanga D'Ajuda, Estância, Indiaroba e Santa Luzia do Itanhi. O objetivo da citada pesquisa foi analisar o potencial turístico da região. Nesse enfoque, inventariou a região que contempla os quatro municípios, espaços rurais que sejam potencialmente atraentes justificando uma visitação por parte dos turistas. Para estruturação do estudo, foram realizadas pesquisas bibliográficas, digital, bem como, coleta de dados por meio da realização de pesquisa de campo com visitas técnicas para análise da região e registro fotográfico. Diante deste potencial facilmente associado ao tradicionalmente explorado turismo de sol e praia, esse presente trabalho, apresenta o desafio de incorporar os pequenos produtores e equipamentos de estabelecimento rurais com potencial turístico em novos roteiros que justifiquem a prática do turismo neste segmento.

Palavras-chave: Litoral Sul de Sergipe. Turismo Rural. Empreendedorismo. Viabilidade Econômica.

\section{ABSTRACT}

The present study included the feasibility process of rural tourism on the coast south of Sergipe, includes the municipalities of Brazil Itaporanga D'Ajuda, Estância, Indiaroba e Santa Luzia do Itanhi. The objective of this research was to analyze the tourism potential of the region. In this approach, whether inventoried the region that covers the four counties, rural areas that are potentially attractive justifying a visitation by tourists. For structuring the study, was make bibliographic searches, digital, as well as data collection by means of conducting field research with technical visits to the region and photographic record. Given this potential easily associated with the traditionally exploited sun and beach tourism, this present work, presents the challenge of embedding small producers and rural establishment with tourist potential in new scripts that justify the practice of tourism in this segment.

Keywords: South Coast of Sergipe. Rural Tourism. Entrepreneurship. Economic Viability. 


\section{INTRODUÇÃO}

Sergipe tem características peculiares, pois mesmo sendo um estado de pequenas dimensões (cerca de $22.000 \mathrm{~km}^{2}$ ) e localizado entre dois grandes pólos receptores de turismo (Salvador e Recife), possui significativo potencial turístico. Além disso, o estado possui 163 $\mathrm{km}$ de praias pouco exploradas, com água morna limpa e cinco estuários de rios, além de deter uma diversidade no folclore, culinária, artesanato, arquitetura e manifestações culturais (PDITS do Polo Costa dos Coqueirais, 2012). ${ }^{1}$

O Litoral Sul Sergipano diz respeito ao trecho que vai do rio Vaza-Barris até o rio Real, incorporando os municípios de Itaporanga d'Ajuda, Estância, Santa Luzia do Itanhy, Indiaroba e os estuários dos rios Real e Piauí (Figuras 1 e 2). De acordo com o Instituto Brasileiro de Geografia e Estatística, a população total é de 123.628 (Brasil, 2010a), sendo que $39,23 \%$ deste total encontra-se no meio rural.

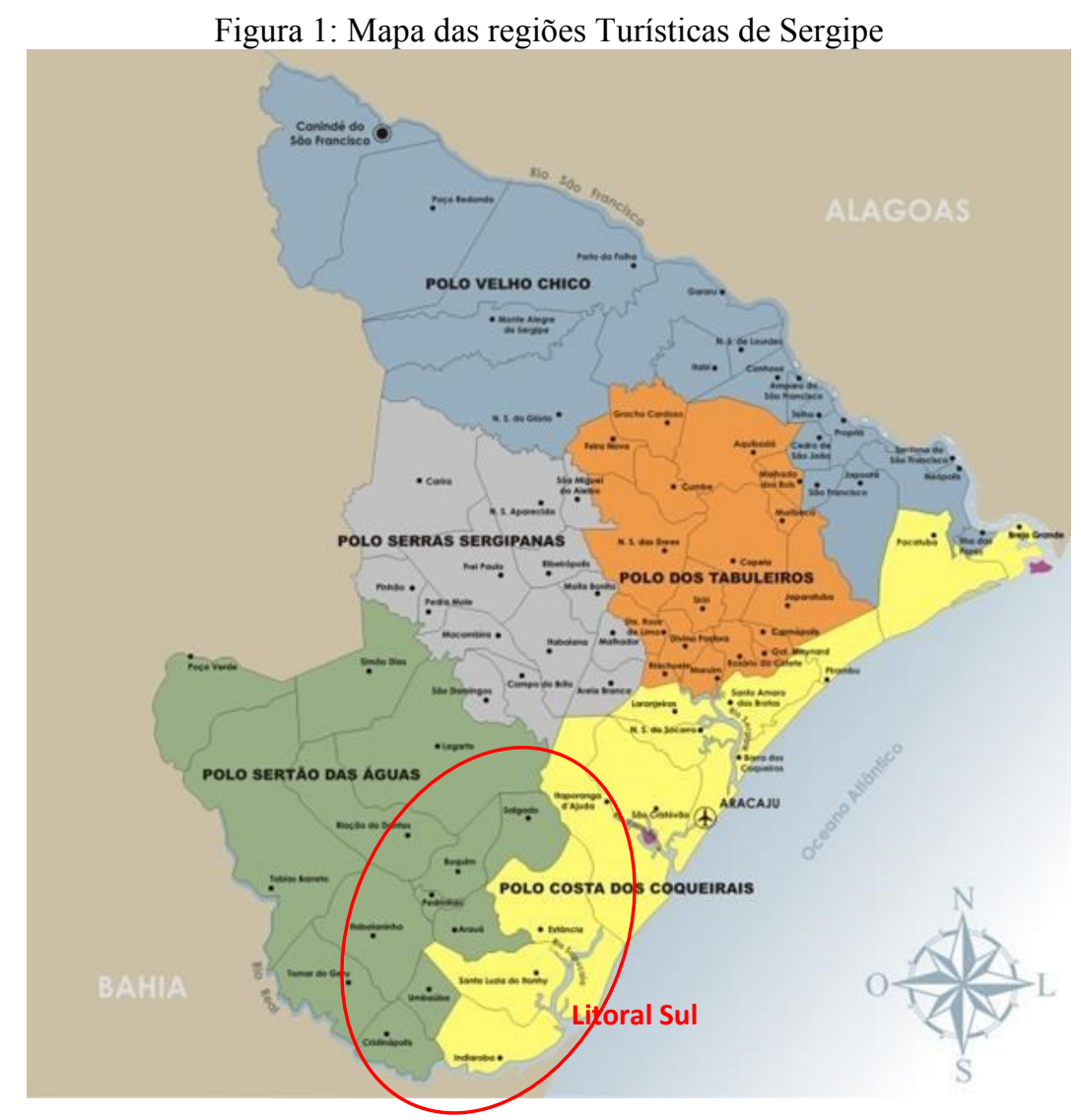

Fonte: PDITS, 2012

\footnotetext{
${ }^{1}$ PDITS - Plano de Desenvolvimento Integrado do Turismo Sustentável, neste caso, da região intitulada Pólo Costa dos Coqueirais que inclui a área do litoral sul, objeto deste estudo. O documento referência é de 2012 na sua terceira versão.
} 
A área sul litorânea de Sergipe se caracteriza por apresentar atrativos naturais e empreendimentos turísticos, bem como micro e pequenos empreendedores da produção associada ao turismo, notadamente a pesca e a agricultura, que desenvolvem suas atividades ainda de forma individual e sem usufruir das possibilidades que uma rota turística bem estruturada proporciona. Esta dificuldade reflete-se inclusive na falta de dados e informações sobre o setor turístico na região, o que justificou, por parte do SEBRAE/SE, a elaboração do Estudo de Viabilidade Econômica e de Mercado, no ano 2014.

Figura 2 - Região Sul de Sergipe

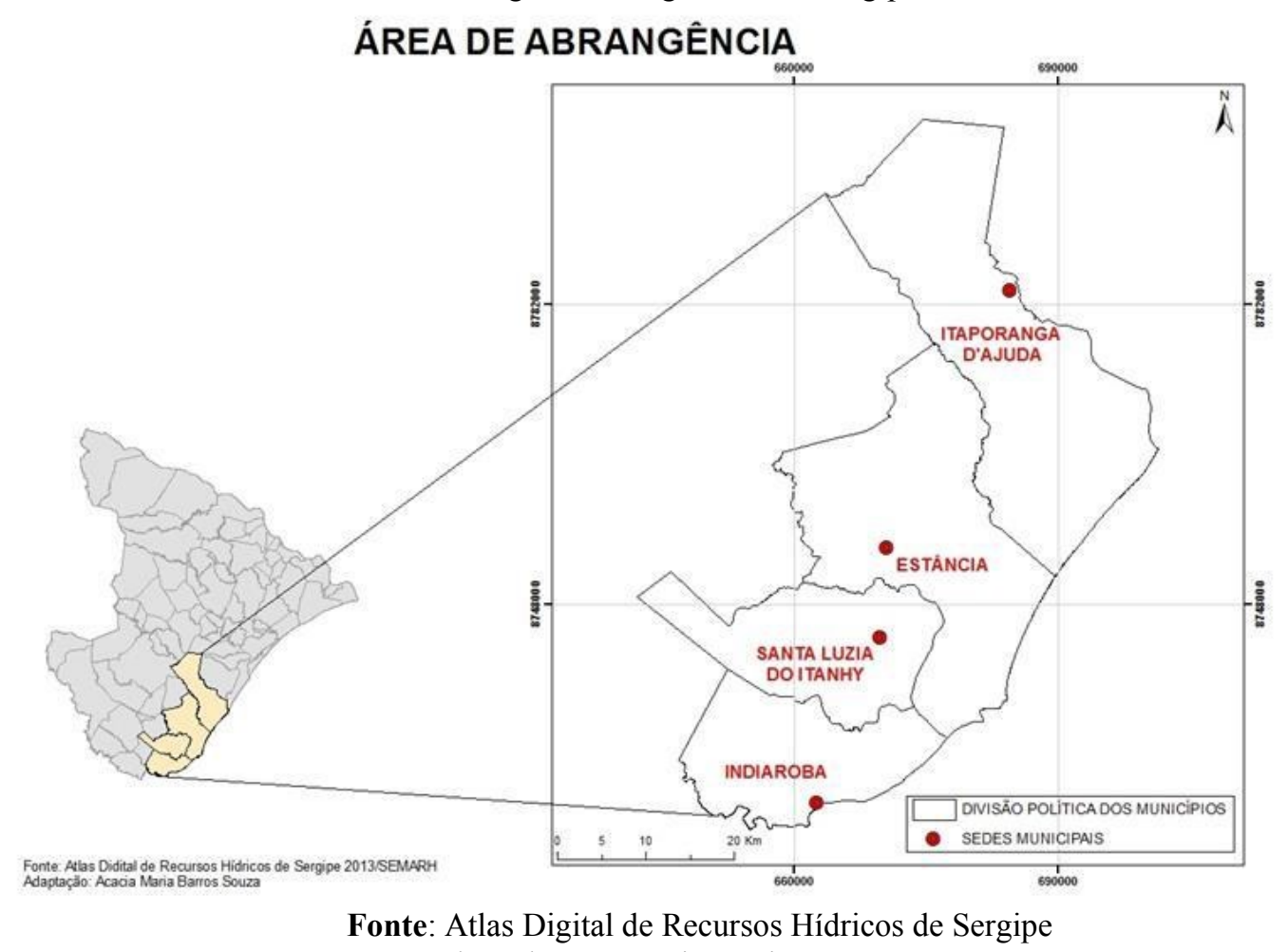

Adaptado por Acacia Maria Barros Souza

Os métodos e técnicas de pesquisas utilizados para o estudo abarcaram pesquisa bibliográfica, digital e documental, além da coleta de informações em entrevistas e observação direta in loco. A pesquisa de campo ocorreu em meses diferentes no ano de 2014, com visitas técnicas nos municípios de Indiaroba, Santa Luzia do Itanhi, Itaporanga D’Ajuda e Estância para análise e coleta de dados e apreensão de imagens por meio da câmera fotográfica. O Estudo de Viabilidade Econômica e de Mercado teve, como objetivo, inventariar na região que contempla os quatro municípios, lugares e projetos sociais, localizados na zona rural, que fossem potencialmente atraentes e capazes de motivar a visitação turística.

No trabalho de campo aconteceram oficinas para sensibilização da comunidade local 
quanto à importância dos atrativos da região, bem como escutas da população local sobre os elementos de identidade cultural apontado por eles. Foi possivel ainda, vislumbrar as áreas rurais da região para o desenvolvimento do turismo, bem como constatar a existencia de atrativos turísticos que completem e justifiquem visitação a estas fazendas.

\section{TURISMO RURAL E PROPRIEDADES RURAIS COM POTENCIAL TURÍSTICO NO LITORAL SUL DE SERGIPE}

A abordagem, nesta etapa, se refere à análise das condições atuais para práticas de Turismo Rural que, conforme o conceito proposto pelo Ministério do Turismo, é o "conjunto das atividades turísticas desenvolvidas no meio rural, comprometidas com a produção agropecuária, agregando valor a produtos e serviços, resgatando e promovendo o patrimônio cultural e natural da comunidade" (Brasil, 2002, p. 49). Ainda sobre o que abrange Turismo Rural, de acordo com a Revista Panorama do Turismo Rural e Agricultura Familiar (2007, p. 5):

\footnotetext{
Este conceito contempla uma diferenciação em relação do Turismo no Espaço Rural, que diz respeito a práticas turísticas que ocorrem no espaço rural, mas não são, necessariamente, Turismo Rural, e sim atividades de lazer, esportivas, que ocorrem alheiras ao meio em que estão inseridas. Estas atividades podem se referir a várias modalidades definidas com base na oferta: turismo ecológico ou ecoturismo, turismo de aventura, turismo de negócios, turismo de saúde, turismo cultural, turismo esportivo.
}

Nos ultimos anos à busca por novos espaços para praticas de descanso e recreação tem aumentado sobremaneira para além de lugares urbanos. Somado ao valor da preservação do meio ambiente e valorização da sustentabilidade, o turismo rural tem despontado como pratica do turismo em que está embutido o valor dos aspectos locais em que pesam a identidade, cultura, oficios e atividades agricolas.

No turismo rural a complementaridade entre turismo e agricultura familiar tem sido observada em propriedades onde o valor de atratividade encontra-se em atividades econômicas típicas deste tipo de agricultura. Disposto a valorizar, respeitar e compartilhar modos tradicionais de vida, patrimônio cultural e natural, produtos e serviços de qualidade são ofertados proporcionando bem estar aos envolvidos: visitantes e visitados. Para Bovo, Logatto e Pimentel (2006), as vantagens potenciais do turismo rural na agricultura familiar seriam a revitalização do espaço rural; inserção competitiva de pequenas propriedades no mercado; valorização da policultura; emprego de mão-de-obra; recuperação da auto-estima; 
dinamização econômica local; valorização da cultura; preservação do meio ambiente.

Observa-se que nos últimos anos a organização do turismo no litoral sul de Sergipe tem se utilizado do segmento de sol e praia para promoção e comercialização do destino, nessa configuração acaba fazendo incipiente uso de produção agrícola e raramente se encontra um produtor rural envolvido com a atividade turística, embora o Estudo realizado tenha apontado para o grande potencial do turismo rural.

Este potencial se dá pelo aproveitamento dos recursos presentes no meio rural para o desenvolvimento do turismo e não se limita apenas à existência de propriedades, abarcando também os atrativos e produtos existentes no campo produzido como bens cultrais da região. Como informa Ruschmann (1997), o espaço de produção de elementos vinculados ao cotdiano e constumes no meio rural é um aspecto significativo no desenvolvimento do turismo, para a fidedignidade e originalidade do entorno, sendo impossível desconsiderar a cultura como uma das princdipais motivações das viagens. A seguir, estão relacionadas atividades identificadas em campo que agregam valor ao produto turístico a ser criado na região estudada:

- Bebidas e alimentos in natura - peixes; frutas, legumes e verduras orgânicas - ou processados como doce, mel, cachaça;

- Artesanato e outros produtos associados ao turismo;

- Criação de animais (gado, ovelhas, cabras e aves);

- Atividades de pesca;

- Atividades de ecoturismo, esportes de aventura, caminhadas;

- Atividades pedagógicas no ambiente rural (história, geografia e biologia);

- Manifestações tradicionais, música, dança e tradições religiosas;

- Gastronomia, saberes e fazeres locais;

- Atividades recreativas no meio rural;

- Visitação a fazendas, antigos engenhos de açúcar.

Cada município tem uma participação dinâmica na organização do espaço do litoral sul para funções da prática de turismo rural.

\subsection{Itaporanga d'ajuda}

Fundado em 1846, o município está localizado às margens do rio Vaza Barris, a 31 Km da capital sergipana (Mendonça \& Silva, 2009), (Sergipe, 2013). Possui aproximadamente 30 mil habitantes e área de $740 \mathrm{Km}^{2}$. Abriga grande diversidade cultural, 
com destaque para a culinária, religião e festas típicas. Dentre as belezas naturais destacam-se a Praia da Caueira e a Ilha Mem de Sá.

Em termos de turismo rural o município se destaca em função do acentuado número de fazendas históricas preservadas: 5 fazendas e 3 engenhos. Conforme constatado em visita técnica, no interior das casas grandes presentes nas fazendas um acervo de objetos, como quadros, castiçais e peças de mobiliário contam a história de uma aristocracia de descendência portuguesa que viveu no estado e foi responsável pela ocupação e povoação das terras que hoje conformam o município. Foram visitadas as fazendas Escurial, Belém e Dira (Figuras 3, $4,5$ e 6$)$.

O Engenho Dira, possui como principal atividade econômica a criação de bovinos e ovinos. Nos últimos anos, ressalta-se a diversificação da atividade econômica com investimentos em piscicultura. Em toda extensão do engenho, pode-se observar açudes, mirantes, resquícios de mata atlântica e uma natureza exuberante. Sua história se mantém preservada tanto através da casa grande quanto da igreja, onde podem ser encontradas lápides dos primeiros moradores da fazenda.

Figuras 3, 4, 5 e 6 - Fazendas Escurial, Belém e Dirá
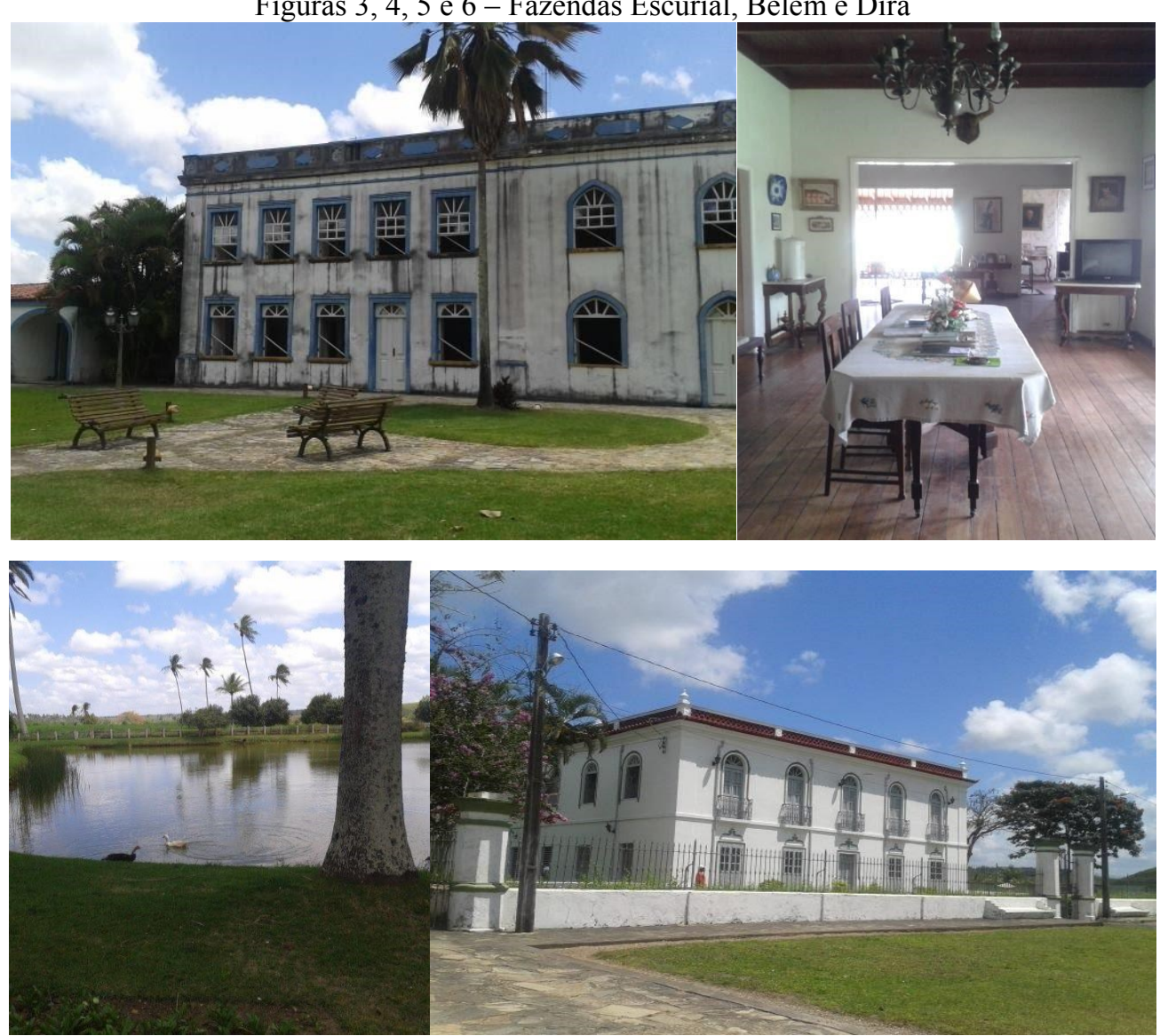

Fonte: SEBRAE, 2014 
A fazenda Colégio é considerada historicamente como o primeiro engenho do Estado de Sergipe. Tombado pelo patrimônio histórico nacional, as primeiras edificações, tais como o Engenho do Colégio Itaporanga D’Ajuda e a Igreja Nossa Senhora D’Ajuda (Figura 7), foram construídas para abrigar os primeiros padres jesuítas, que chegaram ao estado em 1575 (Santos 2011). Na propriedade destacam-se o sobrado e a igreja, as casas dos trabalhadores e uma segunda casa, sendo esta mais moderna.

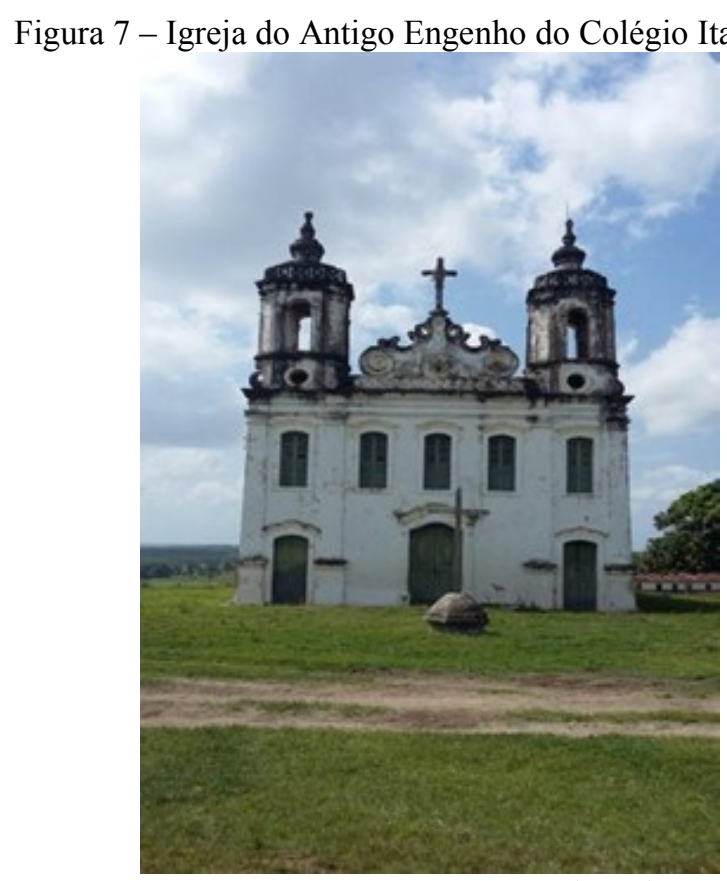

Fonte: Ivan Rêgo Aragão (2015)

Outro engenho registrado na cidade é o Itaperoá, na qual da construção original quase nada restou, a não ser a chaminé da antiga usina. No entanto, a propriedade destaca-se tanto pela facilidade no acesso quanto pela variedade de atividades agropecuárias realizadas no local, que vão desde a pecuária de corte passando pela criação de ovinos e de búfalos.

O engenho Belém, encontra-se espalhado em seus 650 hectares, sendo possível encontrar riachos, nascentes de água mineral, mata atlântica nativa e o rio Vaza Barris. Como acervo histórico, destaca-se a casa grande, que apesar de não manter por completo sua estrutura original devido às várias reformas pelas quais passou, mantém, em seu interior, móveis e objetos que contam a trajetória da família. Sobreviveram ao tempo ainda uma capela particular, a chaminé da usina e o cemitério da família Freire.

\subsection{Estância}

De acordo com Mendonça e Silva (2009) e Santana (2011), o municipio de Estância foi fundado em 1831. Denominado de “Cidade Jardim” pelo Imperador Dom Pedro II, guarda 
em suas praças, ruas e monumentos uma atmosfera bucólica bastante atrativa. Suas festas também possuem grande expressividade como a Festa de São João, que atrai turistas de diversas partes do Brasil.

Em termos de Turismo Rural, destaca-se o Engenho Kassunguê. A fazenda, além de manter em sua estrutura a casa grande e a igreja, destaca-se pela instalação de um Haras.

\subsection{Santa Luzia Do Itanhi}

Fundada em 1698, o município tem $336,2 \mathrm{~km}^{2}$ de área total e população de 13.914 hab. (Brasil, 2010a). Está inserido na bacia hidrográfica do rio Piauí, na região sul-sudeste do Estado de Sergipe. Possui riqueza natural caracterizada pelos mangues e pela mata atlântica. Merece destaque a Reserva Ecológica do Crasto e os engenhos de açúcar ainda presentes e em bom estado de conservação.

A herança da Cultura Ibérica se mescla com influências nativas da cultura indígena e manifestações da África para ressoar em inúmeras artes de fazer do expressivo patrimônio imaterial de Santa Luzia do Itanhy: nos bordados redendê e ponto-cruz, nos trançados de fibras naturais, nas artes de rezar, na rica culinária à base de ensopados de peixes e crustáceos. Elementos culturais atrativos, visto que, buscam valorizar as atividades relacionadas à vivência do conjunto de elementos significativos do patrimônio histórico e cultural [...] dos bens de natureza material e imaterial que expressam ou revelam a memória e a identidade das populações e comunidades (Brasil, 2010c).

Considerado o segundo engenho mais antigo de Sergipe (1632), o Engenho São Felix foi tombado como patrimônio do Estado em 1984 (Loureiro, 1999). Sua infraestrutura se encontra em bom estado de conservação e suas características originais foram preservadas (Figuras 8 e 9). Além dos móveis coloniais, a propriedade conserva o porão onde, segundo informam os atuais proprietários, os escravos eram alojados. A fazenda conta ainda com 250 hectares onde, outros recursos naturais, podem ser encontrados pequenos córregos, nascentes, mata atlântica e estruturas históricas como a chaminé da antiga usina.

Praticamente não existe restrição por parte do proprietário à entrada de visitantes no interior da fazenda. O acesso por carro pode ser feito pela rodovia Camilo Calazans, que possui boas condições. 


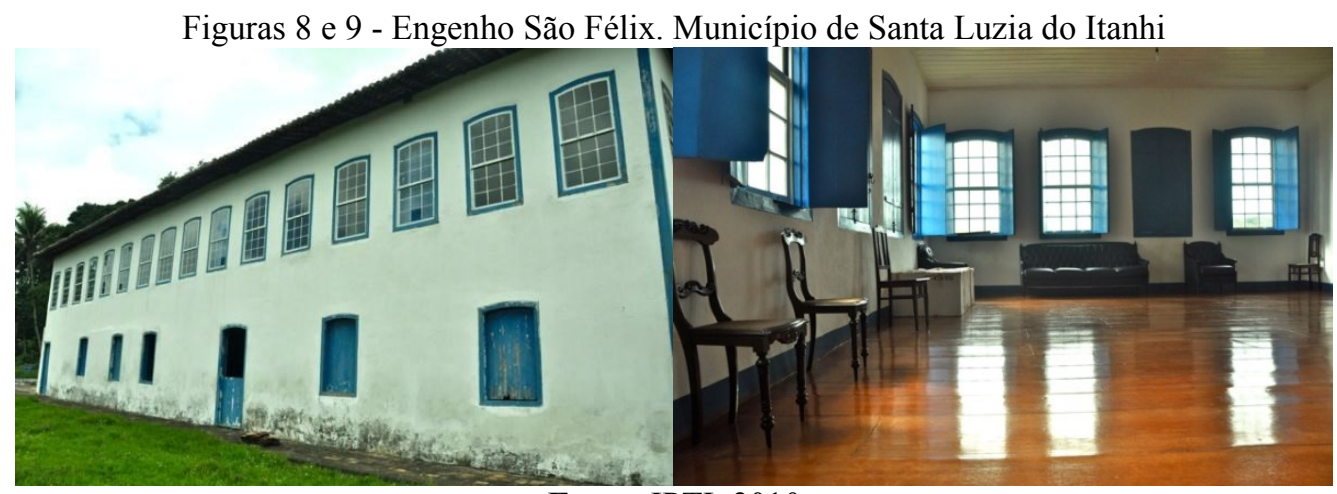

Fonte: IPTI, 2010

Outra atividade econômica que se configura como um atrativo cultural é a produção artesanal de cachaça da fazenda Priapu da Feira, antigo engenho de açúcar, que produz cachaça envelhecida em barril de carvalho, a cachaça Reserva do Barão (Figuras 10 e 11), que já vem sendo comercializada em larga escala, atendendo inclusive a uma demanda internacional. No estado atual, o local, devido à sua boa infraestrutura e por contar com um caseiro que acompanha o visitante, mostrando todas as etapas de produção da cachaça, da moenda até a fase de envasamento da cachaça, se apresenta como um atrativo apto à visitação. Nos meses de produção da cachaça, que acontece entre setembro à janeiro, o proprietário oferece ao visitante uma degustação da cachaça.

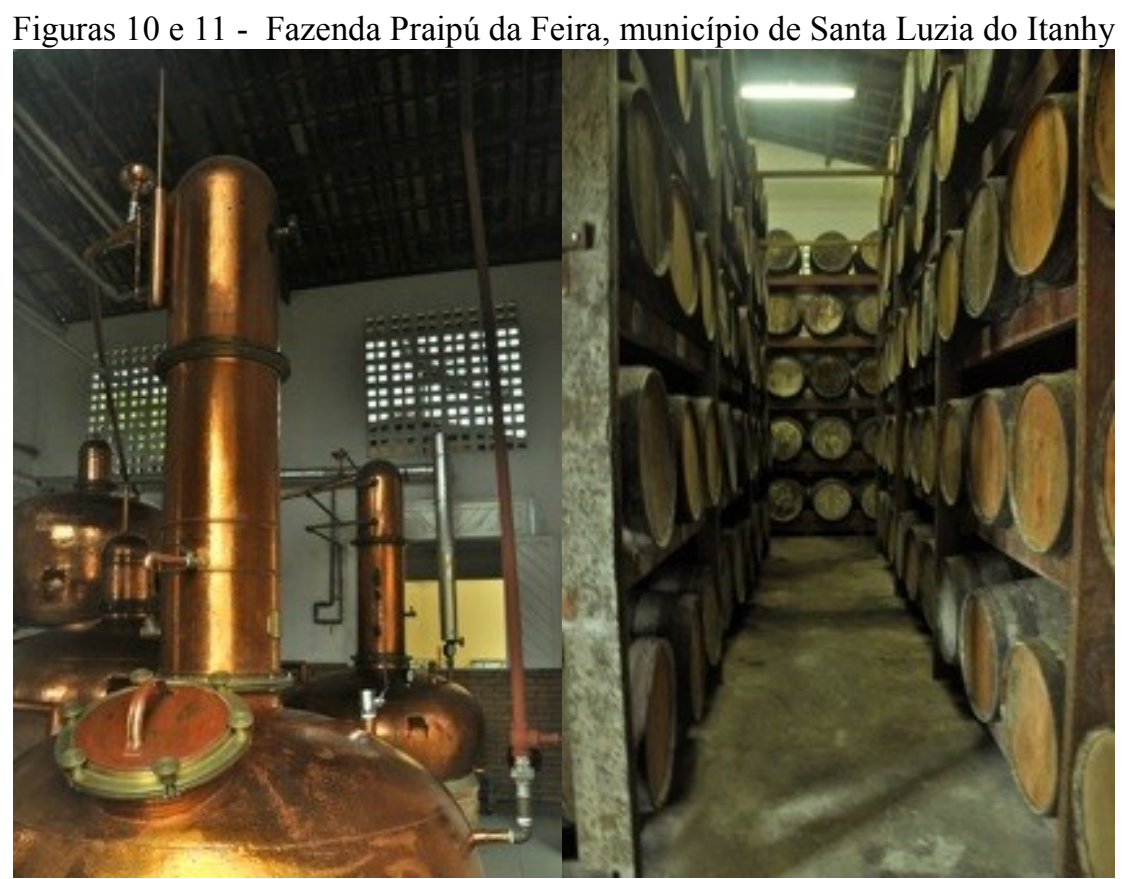

Fonte: Inventário da Oferta Turística, IPTI, 2010

Os funcionários da cachaçaria, apesar da boa vontade para atender os visitantes, necessitam ser capacitados para atender melhor à demanda turística. Não há, nenhuma placa de sinalização indicando a entrada para a Fazenda na rodovia Camilo Calazans, que lhe dá 
acesso. O caminho que deve ser percorrido da estrada asfaltada até a cachaçaria, de barro, também pode, principalmente em dias de chuva, dificultar a chegada até o local.

\subsection{Indiaroba}

O município está localizado no extremo sul do Estado de Sergipe, a $100 \mathrm{~km}$ da capital, Aracaju. Possui área de $314 \mathrm{Km}^{2}$ e 15.821 habitantes (Brasil, 2010a). Apresenta uma diversidade de recursos naturais composta de manguezais, lagoas, dunas, restingas, estuários e remanescentes de Mata Atlântica. Riqueza é também encontrada no modo de vida da população, com suas festas e manifestações folclóricas, como o samba de coco.

Em Indiaroba é possível passar uma tarde apreciando o vai e vem dos barcos à vela (Figura 12) e desfrutar de comidas à base de peixes, mariscos e catados. Além disso, é possível passear pela região rural, povoados Convento, Pontal e Terra Caída onde o maior atrativo é a vida simples e gente hospitaleira com gastronomia à base de peixes e mariscos. A respeito do patrimônio ambiental com "ar de cidade interiorana", Aragão, Abadia e Tupinambá (2010, p. 85) se referenciam em Yázigi (2001), ao refletir que trata-se:

[..] do maior atrativo turístico local a ser preservado. Uma nova vertente tem pensado na atividade turística como promotora dos saberes locais, firmados na cultura popular e na singularidade dos residentes. Resgatando e valorizando o meio ambiente e a cultura das pessoas inseridas em uma região.

Figura 12 - Barco à Vela no Estuário do Rio Piauí

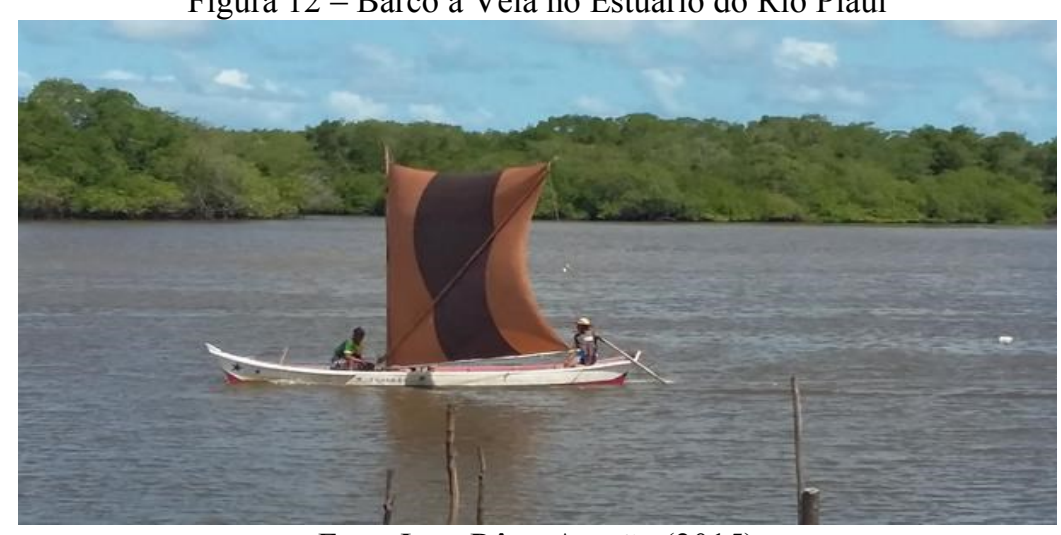

Foto: Ivan Rêgo Aragão (2015)

A comunidade de Terra Caída está inserida na Área de Preservação Ambiental do Litoral Sul do Estado de Sergipe (Decreto 13.468 de 21 de Janeiro de 1993) constituída por manguezais, estuários, dunas, restingas, lagoas e remanescentes de Mata Atlântica. Esses ecossistemas se encontram conservados no entorno do povoado. De modo geral, a área possui 
os seguintes atrativos turísticos pouco explorados: Terapia da mangaba e do massunim; ${ }^{2}$ Pescaria no estuário; Passeios pelos manguezais em barcos à vela; Passeios de jegue, charrete e bicicleta; Trilhas para trekking; Turismo náutico de velejadores.

Terra Caída já possui atividades turísticas no seu cotidiano em função de ser um dos acessos a praia de Mangue Seco, localizada no município de Jandaíra (BA), conhecida nacional e internacionalmente pelo romance e novela Tieta do Agreste, de Jorge Amado. As estradas de acesso se encontram em boas condições. Os pescadores da Associação pela Cidadania dos Pescadores e Moradores do Povoado Terra Caída oferecem transporte marítimo em barcos à vela ou a motor para Mangue Seco. As operadoras de turismo Ibero Star (Salvador), Nozes Tur (Aracaju) e Gazela (Estância) transportam os turistas e atracam suas embarcações em Terra Caída para almoço no restaurante da comunidade, que oferece comida típica de qualidade.

Apesar de contar com duas pousadas, poucos turistas se hospedam no povoado, que também possui várias casas de veraneio. A maioria dos turistas chega à localidade em veículo próprio, advindos de Aracaju e Bahia. Esses turistas, muitas vezes, param no povoado para se alimentarem antes de fazerem a travessia pela balsa Terra Caída (Indiaroba) - Porto Nangola (Estância) rumo à Aracaju.

A estruturação do turismo no Povoado Terra Caída está diretamente relacionada à principal atividade econômica da região, a pesca artesanal, que se apresenta organizada em forma de associação: Associação pela Cidadania dos Pescadores e Moradores do Povoado Terra Caída.

\section{ANÁLISE DO TURISMO RURAL NO BRASIL}

No turismo rural, quando agricultores familiares e demais agentes produtivos do espaço rural se associam de maneira inovadora e buscam valorizar e preservar o patrimônio local (Brasil, 2002 \& 2007), o produtor rural passa a ser um empreendedor e prestador de serviços turísticos, podendo trabalhar diretamente na conservação do patrimônio ambiental e cultural de sua região. A relevância da atividade do turismo rural em áreas onde há predominância da agricultura familiar pode ser constatada, à medida que essa associação se reverte em novas oportunidades de trabalho e renda, pois, nestes casos, a economia local é ativada por meio da diversificação de novas formas de trabalho no campo.

Ao apresentar os modos tradicionais e artesanais da agricultura familiar como

\footnotetext{
${ }^{2}$ Viver a experiência de catar mangabas e massunins em seu habitat natural ouvindo as histórias e músicas dos
} catadores e, após as atividades em campo, saborear o que foi catado em prato regional. 
produto turístico, o turismo rural amplia suas possibilidades, consolidando o modo de vida rural como um atrativo aos moradores de outras regiões. $\mathrm{O}$ estilo de vida, os costumes e o modo de produção das famílias rurais, ou seja, a cultura do campo passa a despertar o interesse não apenas dos moradores dos grandes centros urbanos, mas também dos municípios vizinhos. Neste sentido, as atividades não agrícolas assumem um papel relevante na composição da renda total das famílias rurais, podendo ser consideradas altamente estratégicas para o crescimento socioeconômico local.

As averiguações empíricas presentes neste Estudo são fruto de nosso percurso de pesquisa nas áreas rurais do interior e da zona costeira do sul sergipano. Nestas localidades, o turismo se apresenta como mais uma opção de desenvolvimento para pequenas comunidades de pescadores, agricultores familiares e extrativistas. Ao proporcionar a ampliação das práticas cotidianas em suas terras, o turismo se insere, segundo Bartholo, Sansolo \& Bursztyn (2009), em um conjunto de atividades que representam uma nova multifuncionalidade dos espaços rurais.

Ao buscar novas alternativas de sobrevivência, para além da subsistência tradicional, pequenos grupos de agricultores, pescadores e extrativistas passam a atuar como agentes da nova construção social rural, em que a terra passa a ser concebida com valores potenciais múltiplos, por sua multifuncionalidade (Blanco, 2004 apud Bhartolo, Sansolo \& Bursztyn, 2009). Este termo também é adotado por Muller (2007) apud Bhartolo, Sansolo \& Bursztyn (2009) e abarca atividades tais como a tradicional produção agrária, os serviços ambientais que ela pode oferecer os valores cênicos e paisagísticos e a própria cultura derivada da relação entre os habitantes e o meio onde vivem.

Dentre estas novas funções, o turismo tem sido uma opção adotada por famílias e pequenos proprietários rurais e vem sendo apoiado pelo poder público brasileiro desde início da década de 1990 por meio de políticas públicas setoriais provenientes do Ministério do Desenvolvimento Agrário (MDA), Ministério do Meio Ambiente (MMA) e Ministério do Turismo (MTUR).

O MDA apresenta o turismo como uma atividade não agrícola com potencial para a geração de trabalho e renda que pode auxiliar a conservação ambiental e a valorização cultural camponesa. Dessa forma, conduz o Programa Nacional de Turismo na Agricultura Familiar, cujo objetivo é promover o desenvolvimento regional e fomentar as atividades turísticas entre os agricultores familiares sempre integrados aos arranjos produtivos locais 
(Brasil, s/d).

A associação entre o turismo rural e a agricultura familiar tem despertado tanto interesse que o Ministério do Desenvolvimento Agrário criou, em 1995, uma linha especial de crédito do Programa Nacional de Fortalecimento da Agricultura Familiar (Pronaf): o Pronaf Turismo Rural. Através desta linha, incentiva-se a implantação de projetos em propriedades familiares, como cafés coloniais (esta versão é encontrada na região sul do país, no caso de Sergipe, poderia ser oferecido o tradicional café-da-manhã nordestino), pousadas, estabelecimentos do tipo pesque-pague ou colha-pague, restaurantes, entre outros.

Apesar de criticas ao trade turistico que é visto como manipulador dos reais interesses do turismo rural em que pesam o protagonismo do pequeno e medio produtor local, pois apoia "a inserção de atores do trade turístico nas ações referentes ao TRAF, incorporando a lógica vertical das instituições representativas do turismo, que muitas vezes se choca com uma lógica horizontal e menos gananciosa dos agricultores familiares" (Candiotto, 2013, p. 129). A parceria entre a forma do segmento do turismo rural com a agricultura familiar, traz alternativas de viabilidade economica para o homem do campo e produtor rural no setor turistico.

Outra medida adotada pelo governo brasileiro (MDA) em 2004 foi a criação da Rede Traf (Rede de Turismo Rural na Agricultura Familiar), um grupo de articulação nacional envolvendo mais de 100 instituições, com apoio do Instituto Interamericano de Cooperação para Agricultura e o MDA.

Ainda em 2004, o MTur apresentou as Diretrizes para o Desenvolvimento do Turismo Rural Brasileiro. Os objetivos expostos pelas diretrizes evidenciam um privilégio ao incremento econômico da atividade, considerada como um segmento turístico. Dentre outros aspectos, chama atenção, a abordagem territorial cujas diretrizes apontam o turismo rural como um fator indutor ao desenvolvimento regional, tendo o território como ponto de partida para análise e realização de investimentos em infraestrutura.

Em 2008, o MTur passou a reconhecer institucionalmente a existência do Turismo de Base Comunitária (TBC), ao publicar um edital voltado ao fomento das atividades produtivas vinculadas ao turismo comunitário (MTur, n. 001/2008). No edital, o Ministério define TBC da seguinte forma:

O turismo de base comunitária é compreendido como um modelo de desenvolvimento turístico, orientado pelos princípios da economia solidária, associativismo, valorização da cultura local e, principalmente, protagonizada pelas comunidades locais, visando à apropriação por parte dessas, dos benefícios advindos da atividade turística. 
Embora o edital não tenha definido a espacialidade do TBC, uma análise preliminar permite inferir que dos 50 projetos selecionados para financiamento, cerca de $80 \%$ estavam ou eram vinculados às áreas rurais, tanto do interior do Brasil quanto da região costeira, o que traduz a importância deste tipo de atividade hoje no país (Bartholo, Sansolo \& Bursztyn, 2009).

No Turismo de Base Comunitária prevalecem as relações de proximidade, de vínculos simbólicos; mas também vínculos territoriais, com o lugar vivido. Grande parte dos casos situados na região nordeste está localizada na região costeira. Cerca de $80 \%$ dos casos estudados ocorrem nas proximidades, no interior ou contêm áreas protegidas, tanto as unidades de conservação de proteção integral quanto as de uso sustentável. No caso do litoral sul sergipano, destaca-se a presença da Área de Proteção Ambiental Sul (APA-Sul), localizada nos municípios de Estância, Indiaroba e Santa Luzia. Nestas áreas, observa-se a ocorrência de manguezais, dunas, restingas, topos de morro, nascentes e margens de rios, o que reforça a ideia de um potencial vínculo entre as questões relativas à atividade turística e a conservação ambiental.

Segundo Bartholo, Sansolo e Bursztyn (2009), as comunidades mais dinâmicas têm procurado abordar as exigências do mercado e suas próprias restrições de duas maneiras: diferenciando o seu produto e educando os seus profissionais. No primeiro caso, busca-se valorizar as manifestações de sua identidade cultural combinando-as com atrativos do turismo ecológico, histórico e recreativo, em função da especificidade dos recursos encontrados no território. No segundo caso, tem-se tomado medidas para preparação dos profissionais na realização das funções complexas inerentes à operação turística e à gestão do negócio.

Em 2015, o SEBRAE/SE deu continuidade ao Estudo de Viabilidade Econômica e de Mercado, promovendo o Inventário do Turismo Rural no Litoral Sul de Sergipe. No âmbito desta ação foram inventariados os quatro municípios da região e ofertadas palestras e os cursos "Atendimento ao cliente" e "Transforme sua ideia em um modelo de negócio" para agentes produtivos da área rural envolvidos direta ou indiretamente com o turismo.

\section{CONSIDERAÇÕES FINAIS}

O desenvolvimento da pesquisa de campo foi capaz de apontar para viabilidade do turismo rural no litoral sul de Sergipe considerando seu potencial atrativo de propriedades rurais nos quatro municípios. Diante deste potencial facilmente associado ao tradicionalmente 
explorado turismo de sol e praia, apresenta-se o desafio de incorporar os pequenos produtores rurais e equipamentos de estabelecimento rurais com potencial turístico em novos roteiros que justifiquem a prática de turismo rural, portanto os seguintes aspectos devem ser considerados na expectativa de viabilidade do novo segmento turístico:

1 - O Turismo Rural demandou a elaboração do inventário da oferta turística da região no ano de 2015;

2- Embora os estados da Bahia e Alagoas sejam os principais concorrentes são também os principais polos emissivos de turistas, portanto futuras ações de promoção deste segmento deverão contemplá-los;

3- A rodovia SE-100 sul, que liga a região do projeto à BR-101 está em boas condições, porém carente de sinalização dos atrativos e equipamentos turísticos;

4- A estratégia de desenvolvimento do Turismo Rural deve levar em consideração as caraterísticas do turismo de base comunitária pela necessidade de protagonismo local e residentes como sujeitos da ação deste novo turismo;

5- Os órgãos oficias de Turismo, Agricultura e Cultura do Estado e dos municípios devem ser mobilizados para a definição de ações de desenvolvimento do turismo;

6 - Os empreendimentos identificados com vocação para o turismo rural demandam a estruturação de diagnósticos de maturidade de gestão, também elaborados pelo SEBRAE/SE em 2015 ;

7 - Os donos de estabelecimento rural (grandes propriedades) devem participar de forma complementar ao projeto. Embora não tenham sido o público alvo, porque são grandes empresários, suas propriedades são reconhecidas como patrimônio material histórico cultural e podem servir de centro de distribuição das produções de pequenos empreendimentos (bovinos, ovinos e caprinos de leite e corte, produtos orgânicos, artesanato, entre outros); 8- A promoção da região a partir da criação de campanha publicitária incluindo vídeo documentário do potencial da região, alcançando os operadores e agências de turismo, além do empresariado local, organizações públicas e a comunidade em geral;

9- A comercialização do Turismo Rural demanda a construção de roteiro turístico específico sobre o turismo rural (cardápio dos atrativos e serviços turísticos).

Entende-se que a ação de fomento ao Turismo Rural no litoral sul contribuirá para a diversificação da oferta turística na região bem como para o incremento de renda de pequenos produtores rurais capazes de conjugar o turismo com suas atividades atuais. Esta estratégia possibilitará que o turismo no espaço rural integre-se à "atividade agrícola e pecuária, tendo 
como oferta o ambiente natural e suas modificações para atividades agropastoris e cultura local da zona rural, surgindo como alternativa para proprietários rurais na atual crise financeira e fundiária" (Silva \& Moura, 2010, p. 2).

Isto sinaliza a necessidade de continuidade do projeto com a execução de ações de competência de órgãos parceiros que deverão ser inseridos nas discussões a partir do modelo de gestão proposto - cooperativa ou associação - com devido poder de mobilização e articulação capaz de atingir o cenário desejado para iniciar as primeiras operações do turismo rural, com o devido respeito ao uso dos recursos naturais e com a valorização da capacidade endógena na construção dessa alternativa econômica.

\section{REFERÊNCIAS}

Aragão, I. R; Abadia, B \& Tupinambá, K. (2010). Paradoxos entre Taipu de Fora e Taipu de Dentro/ APA de Maraú-Bahia: Turismo e identidade local. Revista Rosa dos Ventos, 2(2), 80-88. Caxias do Sul.

Bartholo, R; Sansolo, D. G \& Bursztyn, I. (2009). Turismo de Base Comunitária: diversidade de olhares e experiências brasileiras. Letra e Imagem. Rio de Janeiro.

Bovo, C. E. O; Logatto, E \& Pimentel, M. (2006). Turismo rural e metodologia participativa ferramentas eficientes para o trabalho da extensão rural em busca do DS. Anais do Congresso Internacional sobre Turismo Rural e Desenvolvimento Susterntável. Santa Maria, RS:

FACOS/UFSM, 167-174.

Brasil. (2002). Marcos conceituais. Ministério do Turismo. Recuperado em 14 de outubro, 2014 de

http://www.turismo.gov.br/sites/default/turismo/o_ministerio/publicacoes/downloads_publica coes/Marcos_Conceituais.pdf. Brasília.

Brasil. (2007). Ministérios do Desenvolvimento Agrário e do Turismo. Revista Panorama do Turismo Rural e Agricultura Familiar. Brasília.

Brasil. (2008). Edital de Chamada Pública de Projetos Mtur $/ n^{\circ} 001 / 2008$ - Seleção de propostas de projetos para apoio às iniciativas de Turismo de Base Comunitária. Ministério do Turismo, Brasília.

Brasil. (2010a). Sinopse do censo demográfico. Recuperado em 11 de novembro, 2014, de http://www.censo2010.ibge.gov.br/sinopse/index.php?uf $=28 \&$ dados $=0$.

Brasil. (2010b). Turismo rural: orientações básicas. (2 ${ }^{\mathrm{a}}$ ed.). Ministério do Turismo. Brasília.

Brasil. (2010c). Turismo cultural: orientações básicas. ( $3^{\mathrm{a}}$ ed.). Ministério do Turismo.

Brasília.

Candiotto, L. Z. P. (2013). O discurso da viabilidade do turismo rural na agricultura familiar: 
o papel do programa nacional do turismo rural na agricultura familiar (PNTRAF) e o papel do estado do Paraná no contexto. Revista de Cultura e Turismo, 7(2), 121-131. UESC, Ilhéus.

Loureiro, K. A. S. (1999). Arquitetura sergipana do açúcar. FUNCAJU, UNIT. Aracaju.

Mendonça, R. U. De \& Silva, Ma . L. M. C. e. (2009). Sergipe panorâmico. (2 ed.). UNIT, Aracaju.

Ruschmann, D. V. M. (1997). Turismo e planejamento sustentável, a proteção do meio ambiente. Papirus, Campinas. (Coleção Turismo).

Santana, R. B. de. (2011). Os espanhóis em Sergipe del Rey. Network, Aracaju.

Santos, A. L. S. M. (2011). Embates entre a cruz e a espada: caminhos da conversão jesuítica na conquista de Sergipe. Anais do XXVI Simpósio Nacional de História - ANPUH, São Paulo, 1-17.

Sergipe (2013). Atlas dos municípios sergipanos. Seplag, Observatório de Sergipe, Aracaju.

Silva, O. V. Da \& Souza, L. P. M. de. (2010). Turismo rural como vetor de desevolvimento economico. Revista Científica Eletrônica do Curso de Bacharelado em Turismo, 7(13), FAHU/FAEF, Garça/SP, 1 - 5.

Yázigi, E. (2001). A alma do lugar: turismo, planejamento e cotidiano em litorais e montanhas. (2 ${ }^{\mathrm{a}}$ ed.). Contexto. São Paulo. Coleção Turismo. 